\title{
UM OLHAR SOBRE A EFETIVIDADE DAS POLÍTICAS PÚBLICAS TRIBUTÁRIAS NA BUSCA DA JUSTIÇA SOCIAL
}

\author{
Maria de Fátima Ribeiro* \\ Lucas Pires Maciel ${ }^{* *}$
}

\begin{abstract}
Resumo:
O presente artigo tem como mote analisar os aspectos sociais que o Estado está obrigado a fornecer à sociedade e as repercussões dos tributos, considerando a tributação como importante instrumento para o desenvolvimento econômico e social. A tributação é necessária não apenas como forma de financiar os custos do próprio Estado, mas para realizar a redistribuição de riquezas. Fez-se um estudo acerca dessa função do Estado e a busca pela Justiça Social. Assim, no cenário nacional, pode-se afirmar que existem políticas públicas para garantir efetivamente a justiça social? Foi utilizado o método dedutivo, com pesquisas bibliográficas.
\end{abstract}

Palavras-Chave: Desenvolvimento Econômico. Incentivos Fiscais. Justiça Social. Políticas Públicas. Tributação.

\section{A LOOK AT THE EFFECTIVENESS OF PUBLIC POLICIES TAXES IN THE SEARCH FOR SOCIAL JUSTICE}

\begin{abstract}
:
This article aims to analyze the social aspects that the State is obliged to provide to society and the repercussions of taxes, considering taxation as an important instrument for economic and social development. Taxation is needed not only as a way of financing the state's own costs, but to realize the redistribution of wealth. A study was made of this function of the State and the search for Social Justice. So, in the national scenario, can one affirm that there are public policies to effectively guarantee social justice? The deductive method was used, with bibliographic.
\end{abstract}

Keywords: Economic development. Tax breaks. Social Justice. Public policy. Taxation.

\section{INTRODUÇÃO}

O presente artigo busca analisar os aspectos sociais que o Estado está obrigado a

\footnotetext{
* Doutora em Direito Tributário pela PUC-SP, Pós Doutora em Direito Tributário pela Universidade de Lisboa, Professora do Programa de Mestrado em Direito da UNIMAR - Universidade de Marília, São Paulo, Brasil, emailmfat@sercomtel.com.br.

** Mestrando em Direito na UNIMAR - Universidade de Marília - São Paulo, Brasil. Especialista em Direito Tributário. Advogado e Professor do Centro Universitário Toledo de Presidente Prudente - São Paulo - Brasil, email lucas_jppm@hotmail.com.
}

Revista de Direito Tributário e Financeiro | e-ISSN: 2526-0138 | Maranhão | v. 3 | n. 2 | p. 23 - 44 | Jul/Dez. 2017. 
fornecer à sociedade e as repercussões dos tributos, considerando a tributação como importante instrumento para o desenvolvimento econômico e social.

O tributo tem como função básica arrecadar recursos para a consecução de financiamento do custos primordiais do Estado, almejando atingir aos objetivos da República Federativa do Brasil, em obediência à Constituição Federal.

Contudo, o tributo não tem apenas essa função. Deve o tributo, também, atender ao seu papel extrafiscal, de interferência na economia, incentivando ou não o consumo de determinado produto ou serviço. Ademais, tem um papel redistributivo, uma vez que recolhe tributo dos mais ricos e repassa aos menos favorecidos, distribuindo melhor as riquezas.

Assim, é de grande valia realizar um estudo acerca dessa função do Estado e a busca pela Justiça Social, para cada vez mais tornar o país menos desigual entre as pessoas e entre as regiões.

Assim, no cenário nacional, pode-se afirmar que existem políticas públicas para garantir efetivamente a justiça social?

Foi utilizado para a construção desse estudo, o método dedutivo, com pesquisas bibliográficas.

\section{POLÍTICA PÚBLICA TRIBUTÁRIA E A FUNÇÃo SOCIAL DO TRIBUTO}

A política econômica que compreende toda a atividade produtiva cedeu lugar à política financeira, que se ocupa do direito público e esta, por sua vez, já deu origem à política tributária que passou a se ocupar exclusivamente das atividades estatais relativas aos tributos (RODRIGUES, 1981, p. 7). Alfredo Augusto Becker (BECKER, 1963, p. 458) ensina que a política fiscal discrimina diferentes espécies econômicas de renda e de capital para sofrerem diferentes incidências econômicas de tributação, no intuito de alcançar seus objetivos econômicos sociais.

A relação entre o Estado e o contribuinte foi caracterizada durante muito tempo como relação de poder e de coerção. Com o constitucionalismo assegurado em meados do Século XVIII, tem-se registro de delimitações das funções do Estado. As Constituições passaram a conter dispositivos que asseguravam os direitos fundamentais evitando o abuso do Estado nas relações jurídicas tributárias.

Revista de Direito Tributário e Financeiro | e-ISSN: 2526-0138 | Maranhão | v. 3 | n. 2 | p. 23 - 44 | Jul/Dez. 2017. 
Em termos constitucionais, destacam-se os princípios que visam delimitar a atuação estatal. Esta atuação insere-se no contexto da política tributária. Tem-se então que a política tributária é o processo que deve anteceder a imposição tributária. É, portanto a verificação da finalidade pela qual será efetivada ou não a imposição tributária.

Gustavo Miguez de Mello (MELLO, 1978, p. 5) assevera que a política tributária deve ser analisada pelos seus fins, pela sua causa última, pela sua essência. Na medida em que o poder impositivo deve questionar: Por que tributar? O que tributar? Qual o grau de tributação?

Atendendo as perspectivas e finalidades do Estado estará executando política pública tributária.

Deve ser ressaltado que a política tributária, embora consista em instrumento de arrecadação tributária, necessariamente não precisa resultar em imposição. O governo pode fazer política tributária utilizando-se de mecanismos fiscais através de incentivos fiscais, de isenções entre outros mecanismos que devem ser considerados com o objetivo de conter o aumento ou estabilidade da arrecadação de tributos.

Assim, a política pública tributária poderá ter caráter fiscal e extrafiscal. Entende-se como política fiscal a atividade de tributação desenvolvida com a finalidade de arrecadar, ou seja, transferir o dinheiro do setor privado para os cofres públicos. O Estado quer apenas obter recursos financeiros.

Através da política extrafiscal, o legislador fiscal, poderá estimular ou desestimular comportamentos, de acordo com os interesses da sociedade, por meio de uma tributação regressiva ou progressiva, ou quanto à concessão de incentivos fiscais. Pode-se dizer que através desta política, a atividade de tributação tem a finalidade de interferir na economia, ou seja, nas relações de produção e de circulação de riquezas.

Misabel Derzi (DERZI, 1989, p. 153) ensina que não é fácil distinguir as finalidades fiscais e extrafiscais da tributação. Seus limites são imprecisos. Assim, entende que a extrafiscalidade somente deverá ser reconhecida para justificar carga fiscal muito elevada, quando se ajustar ao planejamento, definido em lei, fixadora das metas de política econômica e social.

A política fiscal poderá ser dirigida no sentido de propiciar a evolução do país para

Revista de Direito Tributário e Financeiro | e-ISSN: 2526-0138 | Maranhão | v. 3 | n. 2 | p. 23 - 44 | Jul/Dez. 2017. 
objetivos puramente econômicos, como seu desenvolvimento e industrialização, ou também para alvos políticos e sociais, como maior intervenção do Estado no setor privado. A determinação do objeto da política fiscal integra as políticas governamentais.

É ponto pacífico, que cabe à política tributária se ocupar do planejamento e análise dos tributos que devem ser instituídos e cobrados, e, determinar que eles devem ser instrumentos indicados para alcançar a arrecadação preconizada pela política financeira, sem contrariar os objetivos maiores da política econômica e social que orientam o destino do país. José Carlos Graça Wagner (WAGNER, 1982, p. 5/6) destaca que o clamor da sociedade tanto quanto à excessiva presença do Estado na Economia e o consequente nível da carga tributária, como quanto a indagação de qual deve ser o segmento da sociedade que deve pagar a maior parte dos tributos, leva à discussão da própria filosofia do sistema tributário.

É no campo tributário que as implicações atingem toda a sociedade e definem a estrutura econômica da nação. A política pública tributária é o ponto crucial de definição da estrutura da sociedade. Por isso, deve se examinar o fenômeno da tributação em harmonia com dimensão social do homem, sem a qual ele não se realiza integralmente, considerando as dimensões individual e familiar.

Assim, devem ser pesquisados os próprios fundamentos da tributação, para que ela atenda, já na sua origem, as razões de justiça em relação à oneração do tributo. De igual modo o Estado poderá atender suas finalidades através da distribuição de riqueza, satisfação das necessidades sociais, de políticas de investimentos, entre outras, que podem ser alcançadas por meio de uma política tributária e não necessariamente pela imposição tributária. Por isso, é necessário repensar o papel do Estado, na função arrecadatória e na prestação de serviços aos jurisdicionados.

Ao dispor sobre o interesse social e o interesse individual quanto à essência do fenômeno da tributação escreveu Graça Wagner (WAGNER, 1982, p. 19), que não há antagonismo, senão aparente, isto porque o antagonismo surge nos desequilíbrios, tanto quando se estabelecem a favor dos indivíduos como a favor do Estado. A dificuldade de se estabelecer a justa medida, e as razões particularistas, tanto dos indivíduos como do Estado e de seus manipuladores, é que estão na raiz dos conflitos tributários e dos descompassos na justa distribuição dos encargos sobre os diversos segmentos da sociedade.

Daí questionar: No que consiste a tributação social? Não se trata apenas em atender

Revista de Direito Tributário e Financeiro | e-ISSN: 2526-0138 | Maranhão | v. 3 | n. 2 | p. 23 - 44 | Jul/Dez. 2017. 
as necessidades mais elementares da população, é mais do que isso. A tributação deve respeitar a dimensão individual e familiar, considerando a capacidade contributiva do contribuinte.

Sempre que a tributação impedir ou dificultar a realização do essencial em relação à sociedade ou parte dela e até mesmo a uma pessoa, será desmedida e poderá ter caráter confiscatório. Será desmedida também a tributação se os governos pretenderem arrecadar tributos, ultrapassando a soma necessária de dinheiro para o atendimento das necessidades sociais. Tal tributação provoca a transferência de valores dos contribuintes para o fisco, sem finalidade social. Enfim, é tributação social aquela que respeita o que é inerente à sociedade no contexto social dos ditames constitucionais (WAGNER, 1979, p. 310) ${ }^{1}$.

Por isso, referida tributação deve privilegiar as necessidades essenciais da população, destacando-se a alimentação, saúde, vestuário, moradia, educação, acesso ao trabalho, livre iniciativa, livre concorrência entre outros pontos. Na prática, tais posições devem ser efetivadas através de leis isentivas ou com tributações simbólicas. Pelo intervencionismo político-social introduz-se na tributação o fim político-social. O tributo deve ter uma função social, tendendo a uma distribuição do patrimônio e das rendas.

Neste diapasão tem-se que o poder tributante, ao elaborar sua política tributária, deve levar em conta se o sistema tributário é justo, ou seja, se ele trata, de maneira igual todos os contribuintes que se encontram em situação idêntica, e também se está adequado à distribuição de rendas e ao desenvolvimento econômico. E mais, se favorece à política de estabilização da economia, combate do desemprego, à inflação entre outros aspectos.

O fator econômico é preponderante para a adequada política tributária, não podendo o Estado, interferir através da tributação, com medidas que provoquem instabilidade na economia. A estabilidade econômica é mantida quando o Estado controla a inflação, a política de juros, possibilita a capacidade produtiva da sociedade, controla o orçamento público e os gastos públicos, garantindo a propriedade, propiciando a livre iniciativa e a livre concorrência. A política tributária deverá se adequar ao ordenamento jurídico vigente, sob pena de tornar-se ineficaz e nula.

\footnotetext{
${ }^{1}$ Escreve o autor: A tributação social se atende ao que cumpre ao Estado, por força de sua própria razão de ser, não podendo este, sob a alegação de ser o anseio da sociedade, transcender ao seu fim natural, para ingressar na esfera das demais dimensões humanas. A própria lei tem um limite, que transcende. Esse limite é a natureza humana.
}

Revista de Direito Tributário e Financeiro | e-ISSN: 2526-0138 | Maranhão | v. 3 | n. 2 | p. 23 - 44 | Jul/Dez. 2017. 
No tocante à perspectiva de uma reforma constitucional tributária, pode-se questionar: Em que medida tal reforma contempla questões sociais? Referida reforma deverá promover prioritariamente, a função social do tributo, redistribuindo riquezas, promovendo a justiça social. Ao comentar sobre a proposta de emenda constitucional de reforma tributária desejável, ressalta Germana Moraes, como sendo a que, além de guardar respeito à Constituição Federal, represente os anseios da sociedade brasileira, perseguindo os seguintes objetivos: a) promoção da justiça tributária, valendo-se da função social do tributo, que se presta a redistribuir a renda e diminuir a desigualdades sociais e regionais; b) desoneração da carga tributária, sobretudo das incidências sobre a produção e a atividade econômica; c) simplificação e busca da eficiência do sistema tributário; d) preservação do pacto federativo; e) salvaguarda do estatuto do contribuinte, com respeito aos princípios constitucionais e aos direitos fundamentais. Em síntese, a proposta de reforma constitucional desejável é aquela formatadora de um Sistema Tributário Nacional justo e eficiente (MORAES, 2004, p. 90). De igual modo neste contexto, por exemplo, ao tributar a renda do contribuinte deve deixar intocado o mínimo vital do contribuinte, isto é, aquela porção de riqueza que lhe garanta, e a seus dependentes, uma existência digna de um cidadão, afirma Roque Carrazza (CARRAZZA, 2015, p. 120).

Nesta esteira merece registro o Projeto do Código de Defesa do Contribuinte ${ }^{2}$ que originalmente tramitou no Congresso Nacional, que dispõe sobre a igualdade de condições para o contribuinte e para o fisco, através da implementação de dispositivos que contemplam a justiça fiscal. A tributação, como atividade estatal coordenada e dirigida, também se apresenta na forma de política pública. Assim, política pública tributária deve ser entendida como "o somatório das ações integradas, programas e projetos que constituam um conjunto de comportamentos estatais que visam à efetivação do exercício do poder de tributar” (FERREIRA, 2006, p. 6).

Além da fundamental importância dos ditames das políticas tributária e social, deve ser destacado que o sistema tributário justo é aquele que contempla a sua implementação com base nos princípios constitucionais tributários, norteadores da conduta pública. É nesse sentido também que Alexandre Ferreira (FERREIRA, 2006, p. 3) questiona: a atual

\footnotetext{
${ }^{2}$ Projeto de Lei Complementar n ${ }^{\circ}$ 646/99 de autoria do Senador Jorge Bornhausen de Santa Catarina que tratava dos direitos e as garantias do contribuinte. Atualmente encontra-se arquivado.
} 
política pública tributária brasileira tem sido mecanismo indutor de injustiças sociais, ao proporcionar exclusão social e concentração de renda?

\section{DOS PRINCÍPIOS CONSTITUCIONAIS TRIBUTÁRIOS}

O desenvolvimento das políticas governamentais é prerrogativa do Poder Executivo e deve necessariamente estar vinculada aos fundamentos e finalidades da República, previstos na Constituição Federal. Para tanto, é fundamental a busca da justiça social e, por conseguinte, da justiça fiscal, como forma de desenvolvimento dessas políticas. A própria Constituição Federal reforça o compromisso específico do Estado com a justiça social na tributação, ao estabelecer, ao lado de um direito geral de igualdade (art. $5^{\circ}$, caput), um direito específico de igualdade em matéria tributária (art. 150, II), e de vedação de tributos que não respeitem a capacidade econômica dos contribuintes $\left(\operatorname{art} .145, \S \S, 1^{\circ}\right.$ ) ou que ofendam o mínimo existencial (vedação de confisco - art.150, IV).

Merece considerações neste estudo a análise dos princípios constitucionais da igualdade, da capacidade contributiva, vedação do confisco, razoabilidade e da legalidade tributária.

O princípio da igualdade refere-se ao princípio fundamental de todo o sistema tributário e que, necessariamente deverá nortear as políticas governamentais, pois a "estrutura tributária deve guiar-se no sentido da Justiça Fiscal, e os critérios utilizados deverão ter por meta atingir essa Justiça Fiscal. Ela tem de ser justa, de modo a se fazer com que haja uma adequada distribuição do ônus tributário entre os indivíduos” (CONTI, 1997. p. 11).

Essa adequada distribuição do ônus tributário entre todos os indivíduos está atrelada ao conceito de igualdade, uma vez que somente será atingida a justiça fiscal quando os encargos tributários forem divididos entre os indivíduos que compõem uma sociedade, respeitando suas diferenças, na medida em que o princípio cria uma medida uniforme. "O exame de casos iguais com duas ou mais medidas é injusto. O princípio proporciona tratamento isonômico e imparcial de todos que são compreendidos pelo princípio” (TIPKE e YAMASHITA, 2002. p. 20).

Por conseguinte, para que seja alcançada a justiça fiscal, como forma de proporcionar

Revista de Direito Tributário e Financeiro | e-ISSN: 2526-0138 | Maranhão | v. 3 | n. 2 | p. 23 - 44 | Jul/Dez. 2017. 
o desenvolvimento das políticas governamentais de acordo com os ditames constitucionais, faz-se necessário preservar o princípio da igualdade. Presente no caput do art. $5^{\circ}$ da Constituição, afirma que todos são iguais perante a lei, sem distinção de qualquer natureza, constituindo-se em verdadeira garantia fundamental do cidadão. Em matéria tributária, o princípio da igualdade está reforçado no art. 150, II da Carta Constitucional, afirmando que é vedado a qualquer ente federado instituir tratamento desigual entre contribuintes que se encontrem em situação equivalente. Ou seja, o princípio da igualdade não busca uma igualdade tributária pura e simples, colocando todos os contribuintes na mesma condição. O que ele busca é a igualdade entre todos os indivíduos que estejam em iguais condições (RIBEIRO, 1990. p. 26). Seu "tratamento desigual é interditado para todos os contribuintes que se encontrem em situação equivalente” (MARTINS, 1992. p. 160).

Portanto, pode-se afirmar que o princípio da igualdade tributária busca igualar iguais e desigualar desiguais, na medida de suas desigualdades.

Entretanto, para que se alcance a igualdade entre os indivíduos, é necessária a ocorrência de outro princípio, representando pela capacidade contributiva. Corolário do princípio da igualdade (CARAZZA, 2105, p. 77), o princípio da capacidade contributiva está previsto no art. 145, § $1^{\circ}$, da Constituição Federal. Afirma que "sempre que possível, os impostos terão caráter pessoal e serão graduados segundo a capacidade econômica do contribuinte”. Portanto, o princípio da capacidade contributiva está diretamente relacionado com a capacidade econômica do contribuinte que é representada "pela capacidade que o contribuinte possui de suportar o ônus tributário em razão de seus rendimentos” (CONTI, 1997, p. 34). Por conseguinte, a capacidade econômica é a aptidão do indivíduo de gerar riqueza, enquanto que a capacidade contributiva é a aptidão do indivíduo de pagar os tributos, na medida de sua capacidade econômica.

Referido princípio configura-se como desdobramento do princípio da igualdade, pois a capacidade contributiva é exatamente o respeito à igualdade, na medida em que determina o valor a ser pago a título de tributo por um determinado número de pessoas que estejam em igualdade de condições e difere seu montante, também na medida em que há uma desigualdade entre contribuintes diversos, além de ser expressão da "finalidade (Justiça Fiscal) visada pela Constituição, permeando não só a elaboração, mas, também, a aplicação da lei e das normas constitucionais” (OLIVEIRA, 1988. p. 41). 
O constituinte relacionou o princípio da capacidade contributiva a apenas uma modalidade de tributo (impostos), definindo quais são os fatos econômicos da esfera do contribuinte que indicam sua capacidade econômica (importar, exportar, ter renda, ser proprietário de imóvel rural ou urbano entre outros), possibilitando a incidência do tributo, em respeito à capacidade contributiva. No entanto, pode-se entender que referido princípio deverá ser aplicado aos tributos de maneira geral, e não apenas aos impostos, como direciona a Constituição Federal.

Para que se preserve a capacidade contributiva e para que esta seja realmente alcançada, faz-se necessário analisar os princípios da vedação do confisco e da progressividade, respectivamente.

O Estado brasileiro está estruturado no capitalismo, está fundado na captação do lucro e na preservação da propriedade privada. Todos os tributos, na medida de sua incidência, deverão preservar os valores constitucionais. A capacidade contributiva prevê a incidência de impostos de formas diferentes, de acordo com a capacidade econômica dos sujeitos passivos que deverão arcar com os ônus tributários para a manutenção do Estado e para que este desenvolva os seus objetivos. Entretanto, os tributos deverão preservar parcela do patrimônio do individuo, em respeito ao seu direito fundamental de propriedade (Art. 5 ${ }^{\circ}$ XXII, CF). Essa preservação do patrimônio do cidadão, vedando o caráter expropriatório do tributo é a representação do princípio da vedação do confisco, na medida em que preserva o mínimo vital individual e familiar do cidadão (TIPKE e YAMASHITA, 2002, p. 68.).

Portanto, "confisco tributário consiste em uma ação do Estado, empreendida pela utilização do tributo, a qual retira a totalidade ou parcela considerável da propriedade do cidadão contribuinte, sem qualquer retribuição econômica ou financeira por tal ato" (CASTILHO, 2002, p. 39).

Desta forma merece destacar que o confisco tributário deve ser analisado sob o aspecto da universalidade de toda carga tributária incidente sobre o contribuinte ${ }^{3}$.

\footnotetext{
${ }^{3}$ Se a soma dos diversos tributos, representam carga que impeça o pagador de tributos de viver e se desenvolver, estar-se-á diante de uma carga geral confiscatória, razão pela qual todo o sistema terá de ser revisto, e principalmente aquele tributo que, quando criado, ultrapassa o limite da capacidade contributiva do contribuinte. Cf. Ives Gandra da Silva Martins, A Defesa do Contribuinte na Constituição Federal, in A Defesa do Contribuinte no Direito Brasileiro, IOB, SP, 2002, p. 4.
}

Revista de Direito Tributário e Financeiro | e-ISSN: 2526-0138 | Maranhão | v. 3 | n. 2 | p. 23 - 44 | Jul/Dez. 2017. 
Respeitando-se esse mínimo vital do contribuinte, estar-se-á, necessariamente, cumprindo com os ditames da justiça fiscal, respeitando o princípio da igualdade e da capacidade contributiva. Entretanto, para que a capacidade contributiva possa operar de forma plena, faz-se necessário observar o princípio da progressividade.

O princípio da capacidade contributiva, ao determinar uma forma diferenciada de tributação para diferentes indivíduos e a mesma tributação para aqueles que estejam na mesma situação, estabelece um critério proporcional para a incidência do imposto, na medida em que estabelece alíquotas em forma de percentagem, incidentes sobre as bases de cálculo representadas pelos diferentes fatos jurídicos tributários que demonstram uma capacidade econômica do contribuinte. Em razão dessa diferença de onerosidade entre as capacidades econômicas dos diferentes indivíduos e para que a capacidade contributiva possa realmente desigualar os desiguais, na medida de suas desigualdades, incide o princípio da progressividade, pois por meio deste, o "percentual do imposto cresce à medida que cresce a capacidade econômica contributiva; haverá, assim, um aumento mais que proporcional do imposto com o aumento da capacidade contributiva” (CONTI, 1997, p. 75).

O princípio da razoabilidade por sua vez, é um parâmetro de valorização dos atos do Poder Público para aferir se eles estão informados pelos valores da justiça social. O tributo deve preencher uma série de requisitos para ser considerado como razoável, sendo de fundamental importância a avaliação econômica, política e social elaborada pelos Poderes Públicos por ocasião da normatização tributária, tais como a escolha do fato jurídico tributário, da base de cálculo e da finalidade para a qual o tributo foi instituído, devendo ser buscada sempre a solução que gere menor impacto tributário sobre a base tributante, evitando excessos.

Uma tributação justa e que atende os interesses econômicos e sociais, deverá ser pautada no princípio da legalidade tributária, estatuído no inciso I do artigo 150 da Constituição Federal. Daí considerar as afirmativas de Tipke e Yamashita (TIPKE e YAMASHITA, 2002. p. 20):

[...] as normas de finalidade fiscal de um Direito Tributário justo devem considerar a limitação da capacidade contributiva decorrente das inevitáveis obrigações privadas. O Estado Tributário não pode retirar do contribuinte aquilo que, como Estado Social, tem de lhe devolver. 
Dessa forma, pode-se afirmar que o atendimento dos princípios constitucionais supra mencionados, se revela condição sine qua non para que a tributação atue como instrumento de Justiça Social.

\section{DESENVOLVIMENTO ECONÔMICO, JUSTIÇA FISCAL E JUSTIÇA SOCIAL}

Desenvolvimento econômico não é apenas crescimento econômico e nem tampouco distribuição de riqueza. Pressupõe a distribuição dessa riqueza em favor do bem- estar social e a participação da sociedade.

Uma política pública tributária orientada para o desenvolvimento econômico e justiça social, que não tiver na sua essência o estímulo ao trabalho e à produção

[...] compensando a redução de encargos pela tributação sobre acréscimos patrimoniais, termina por não provocar desenvolvimento econômico nem justiça social e gera insatisfações de tal ordem que qualquer processo de pleno exercício dos direitos e garantias democráticas fica comprometido (MARTINS, 1992, p. 6/7).

De certa forma, para o desenvolvimento econômico nacional, deve ser salientada a redução dos gastos públicos, com um processo de diminuição da carga tributária, capaz de permitir uma maior disponibilidade de recursos para a poupança, investimento ou consumo.

A justa repartição do total da carga tributária entre os cidadãos é imperativo ético para o Estado Democrático de Direito. A política fiscal tem de ser política de justiça e não mera política de interesses. Por isso, se tem que o legislador fiscal não pode editar leis de qualquer maneira. Deve observar os princípios de justiça. Leis fiscais sem relação alguma com a justiça não fundamenta o Direito Tributário. Neste sentido, a “justa repartição da carga tributária total entre os cidadãos é imperativo ético para todo Estado de Direito" (TIPKE e YAMASHITA, 2002, p. 27/28).

A arrecadação de tributos é importante para a economia nacional e internacional, não apenas como fonte de riqueza para o Estado, mas também como elemento regulador da atividade econômica e social. Nesta linha de raciocínio deve ser destacado que para alcançar uma justiça fiscal, os ditames do princípio constitucional da proporcionalidade devem estar

Revista de Direito Tributário e Financeiro | e-ISSN: 2526-0138 | Maranhão | v. 3 | n. 2 | p. 23 - 44 | Jul/Dez. 2017. 
aliados ao princípio da progressividade de alíquotas, na maioria dos tributos. Desta forma estar-se-á alcançando os objetivos da natureza social do tributo com a efetiva aplicação destes princípios constitucionais, possibilitando que o Estado alcance com tributação mais elevada os mais ricos e de forma menos acentuada aqueles que possuem baixo poder aquisitivo, podendo, inclusive, conceder a estes uma isenção no pagamento de tributos. Vale aí o destaque dos cânones de Adam Smith: justiça, certeza, comodidade e economia dos impostos.

Outro princípio fundamental para a busca da justiça fiscal é o princípio da função social do tributo. Fundado no capitalismo, o Estado brasileiro tem como direito fundamental a propriedade privada, possibilitando aos indivíduos o acúmulo de recursos necessários para a sua sobrevivência. Entretanto, também dispõe, em seu art. 50, XXIII, que a propriedade atenderá a sua função social, como forma de se preservar o princípio da igualdade, presente no caput do art. $5^{\circ}$ da Constituição Federal. Por conseguinte, embora se preserve o Estado capitalista, este por sua vez, ganha contornos sociais, no sentido de desenvolver políticas sociais como forma de alcançar seus objetivos sociais (art. 3 193 e seguintes da Constituição Federal). Assim, os tributos também precisam preservar a sua função social, como forma de alcançar a justiça fiscal, como um dos objetivos do Estado brasileiro.

Somente com a socialização dos tributos, através da sua aplicação como instrumento social é que será possível desenvolver uma política social justa e distributiva, nos anseios da nação e como forma de se alcançar as finalidades a que o Estado se prestou a desenvolver através de sua Carta Constitucional, e que devem nortear todo o procedimento dos órgãos que compõem a República. Deste modo, para que o Estado alcance suas finalidades socioeconômicas e desenvolva uma política governamental em prol dessas finalidades, faz-se necessário o respeito ao princípio da justiça fiscal, o qual somente poderá ser alcançado mediante a conjugação dos princípios da igualdade e seus corolários, em conjunto com o princípio da função social do tributo, permitindo a todos os cidadãos viver com dignidade, possibilitando o desenvolvimento econômico adequado ao contexto social.

Daí afirmar que no Estado Democrático de Direito a tributação deve ser justa, buscando-se sempre melhorar a distribuição da carga tributária, devendo ser esta proporcional à capacidade contributiva dos contribuintes, de modo a garantir um mínimo existencial a todos.

A justiça é valor essencial da humanidade. A justiça social, por sua vez, é um dos temas mais relevantes na atualidade. A ordem social na Constituição Federal tem como um 
dos objetivos a justiça social nos termos do artigo 193. Neste sentido, destacam-se os direitos da coletividade decorrentes da justiça social, à existência digna (art. $1^{\circ}$, III), à saúde (art. 196), assistência ao idoso (art. 230) e ao desempregado (art. 6º II), dentre muitos outros. Pode-se entender por justiça social o atendimento ao cidadão dos objetivos da ordem social previstos na Constituição Federal de 1988 em atendimento ao princípio da dignidade humana.

Na conjuntura atual onde:

[...] predomina os ideais do neo-liberalismo, que vem baseado em valores do mercado, avoluma-se as desigualdades sociais, sendo necessário observar com mais acuidade aspectos da tributação em consonância com a justiça social almejada e exigida ${ }^{4}$.

Neste contexto a abordagem se dá "no campo da reflexão e neste sentido é que é colocada a indagação sobre o papel da imputação tributária em atendimento aos anseios de justiça social e fiscal” (RIBEIRO, 2013, p. 2).

A política pública tributária pode tornar-se um poderoso instrumento de reversão de desigualdades sociais quando adequadamente distribuído o ônus tributário entre os diversos agentes privados geradores de riquezas. Desta forma, a tributação deve possibilitar a transferência de recursos individuais dos grupos sociais economicamente privilegiados para aqueles menos privilegiados. Caso ocorra o contrário, é interessante apontar a possibilidade de a política pública tributária, ao retirar parcela da riqueza individual dos grupos menos favorecidos economicamente, ser mecanismo indutor de injustiças sociais, tais como a exclusão social e a concentração de renda (FERREIRA, 2006, p. 12).

Por isso, os poderes públicos ao criar as leis para exigir os tributos devem respeitar princípios como a legalidade, capacidade contributiva, vedação do confisco, proporcionalidade, moralidade, razoabilidade, dentre outros para que se atendam necessidades vitais como saúde, segurança pública, educação, lazer bem como o acesso à justiça.

\section{REPERCUSSÕES ECONÔMICAS E SOCIAIS DOS TRIBUTOS}

\footnotetext{
${ }^{4}$ RIBEIRO, Marcelo Gollo. Tributação e Justiça Social: uma perspectiva filosófica. Disponível em https://jus.com.br/artigos/23866/tributacao-e-justica-social-uma-perspectiva-filosofica. Acesso em 05.ago.2017.
}

Revista de Direito Tributário e Financeiro | e-ISSN: 2526-0138 | Maranhão | v. 3 | n. 2 | p. 23 - 44 | Jul/Dez. 2017. 
Durante muito tempo, a tributação foi vista apenas como um instrumento de receita do Estado. Apesar desta missão, ser por si só, relevante, na medida em que garante os recursos financeiros para que o Poder Público bem exerça seu mister, a verdade é que, pouco a pouco, descobriu-se outra faceta não menos importante na tributação. Atualmente com a predominância do modelo do Estado Social, a despeito dos fortes movimentos no sentido do ressurgimento do liberalismo, não se pode abrir mão do uso dos tributos como eficazes instrumentos de política e de atuação estatais, nas mais diversas áreas, sobretudo na social e na econômica. Como se sabe, um dos valores que têm caracterizado o humanismo é a busca da Justiça Social, como elucida Carlos Araújo Leonetti ${ }^{5}$.

As pessoas têm necessidades reais que precisam ser atendidas. Parte destas necessidades deve ser atendida diretamente pelo Estado. Esta sociedade, inserida no contexto econômico-social, deve ser relacionada também com o contexto internacional, cujos reflexos podem gerar encadeamentos diretos nesta sociedade.

A Constituição Federal de 1988 trouxe em seu art. $1^{\circ}$, os principais fundamentos que motivaram a sua criação, destacando-se a cidadania, a dignidade da pessoa humana e os valores sociais do trabalho e da livre iniciativa.

Verifica-se que os princípios inseridos nesse dispositivo devem fundamentar toda a produção de normas no ordenamento jurídico, uma vez que os fundamentos de todo o Estado Democrático de Direito, necessariamente, precisam ser respeitados por todas as normas do ordenamento jurídico.

Em conjunto com esses fundamentos, a Carta Constitucional traz, em seu art. $3^{\circ}$, os seus principais objetivos, isto é, as suas principais metas e finalidades de sua criação. Destaca como finalidades primordiais do Estado a construção de uma sociedade livre, justa e solidária; a garantia do desenvolvimento nacional; a erradicação da pobreza e da marginalização, além de reduzir as desigualdades sociais e regionais; promover o bem de todos, sem preconceitos de origem, raça, sexo, cor, idade e quaisquer outras formas de discriminação. Para tanto, elenca, em seu Capítulo VII, uma série de normas referentes à Ordem Econômica, uma vez que a economia é pressuposto fundamental de todo Estado capitalista e opera uma função essencial para o cumprimento dos objetivos da sociedade brasileira.

\footnotetext{
${ }^{5}$ LEONETTI, Carlos Araújo. Humanismo e Tributação. Disponível em www.egov.ufsc.br/portal/sites/default/files/anexos/21045-21046-1-PB.pdf. Acesso em 10.ago.2017.
} 
Nessa nova era do capitalismo, a intervenção do Estado nas atividades econômicas faz-se fundamental para o respeito aos seus fundamentos e essencial para o cumprimento de seus objetivos, uma vez que esses valores, elevados à veste de princípio constitucional, orientam toda a produção normativa do Estado, na medida em que representam os anseios de toda a sociedade, uma vez que a:

[...] Constituição é o documento no qual são afirmados, através de princípios jurídicos, os valores fundantes e os objetivos e aspirações de uma sociedade. Os princípios jurídicos representam a afirmação e o reconhecimento constitucional dos direito fundamentais e o expresso desejo de transformação da realidade, mediante a fixação, em sede constitucional, dos fins que devem ser buscados pelo próprio Estado e por toda a sociedade (PONTES, 2000. p. 31).

Por sua vez, a ordem econômica, prevista no Capítulo VII do Texto Constitucional, nada mais é do que instrumento de realização desses princípios, na medida em que, estabelece normas que irão versar sobre as práticas comerciais, buscando seu fundamento de validade nos princípios inseridos no art. $1^{\circ}$ do texto constitucional, em especial nos princípios da valorização do trabalho humano e na livre iniciativa e procurando alcançar os objetivos previstos no art. $3^{\circ}$, CF, com ênfase na existência digna e na busca da justiça social.

O art. 170 ainda traz uma série de princípios referentes à Ordem Econômica, mas que, na verdade, são instrumentos de persecução dos objetivos e de cumprimento dos fundamentos do Estado brasileiro, como bem observa João Bosco Leopoldino da Fonseca: "para que os fundamentos sejam concretizados e para que os fins sejam alcançados, necessário se faz adotar alguns princípios norteadores da atividade da ação do Estado” (FONSECA, 1998, p. 87-88).

Desse modo, os princípios norteadores da Ordem Econômica determinam quais deverão ser as condutas dos particulares em suas práticas comerciais, sempre no intuito de se preservar os valores inseridos no Texto Constitucional e que representam os anseios de toda a sociedade.

Por conseguinte, sempre que houver uma ameaça aos princípios consignados no art. 170 da Constituição Federal, através de uma das previsões inseridas no $\S 4^{\circ}$ do art. 173, o Estado estará autorizado a intervir na atividade econômica de forma indireta, através da

Revista de Direito Tributário e Financeiro | e-ISSN: 2526-0138 | Maranhão | v. 3 | n. 2 | p. 23 - 44 | Jul/Dez. 2017. 
fiscalização, da regulação e do planejamento, almejando preservar os fundamentos do Estado Democrático de Direito e cumprir com os seus objetivos primordiais.

Nessa esteira, a Ordem Social, prevista no Capítulo VIII da Constituição Federal também funciona como um instrumento normativo para se alcançar os princípios inseridos nos artigos $1^{\circ}$ e $3^{\circ}$, na medida em que tem como base o primado do trabalho, e como objetivo o bem-estar e a justiça social (art. 193). Observa-se que a positivação desses valores é influência dos Estados Socialistas, servindo como uma espécie de freio aos ideais liberais que regem as relações comerciais. Basear a Ordem Social no Trabalho, nada mais é do que possibilitar ao trabalhador, à parcela mais frágil da sociedade, o direito de viver com dignidade. Nessa vertente, a Ordem Social objetiva fornecer a todos os indivíduos um completo bem-estar, possibilitando-os o acesso à seguridade social, à educação, à cultura, ao desporto, à ciência, à tecnologia entre outras formas de integração social.

Essa integração entre a Ordem Econômica e Social é fundamental para se alcançar os ideais previstos no Texto Constitucional, na medida em que a economia impulsiona toda a sociedade e possibilita ao Estado a geração de recursos para por em prática suas políticas sociais, possibilitando ao cidadão uma vida digna, fundada no seu completo bem-estar social, pois:

[...] o próprio desenvolvimento social, cultura, educacional, todos eles dependem de um substrato econômico. Sem o desenvolvimento econômico dos meios e dos produtos postos à disposição do consumidor, aumentando destarte seu poder aquisitivo, não há forma para atingirem-se objetivos também nobres, mas que dependem dos recursos econômicos para a sua satisfação (BASTOS, 2003, p. 110).

Cumpre ainda destacar sobre a eficácia dos princípios inerentes ao Estado sócio econômico, uma vez que esses princípios buscam alcançar as finalidades do próprio Estado. Como bem observa José Afonso da Silva:

[...] não há norma constitucional destituída de eficácia. Todas elas irradiam efeitos jurídicos, importando sempre uma inovação da ordem jurídica preexistente à entrada em vigor da constituição a que aderem e a nova ordenação instaurada (SILVA, 2000, p. 81). 
Por conseguinte, todas as normas previstas no texto constitucional possuem uma importância para o ordenamento, pelo simples fato de estarem positivadas em um texto normativo. Por serem princípios informadores das finalidades do Estado, em especial no que se refere à Ordem Econômica e Social, esses princípios possuem uma grande importância, mas, exatamente por se referirem a essas finalidades, apresentam uma grande abstração. São, pois, normas programáticas, uma vez que possuem eficácia limitada, na medida em que apenas informam para onde deverá ir o Estado ${ }^{6}$.

Apesar destas normas, serem programáticas, isto é, dotadas de eficácia limitada, possuem fundamental importância no estudo do direito constitucional, pois:

[...] procuram dizer para onde e como se vai, buscando atribuir fins ao Estado, esvaziado pelo liberalismo econômico. Essa característica teleológica lhes confere relevância e função de princípios gerais de toda ordem jurídica, tendente a instaurar um regime de democracia substancial, ao determinarem a realização de fins sociais, através da atuação de programas de intervenção na ordem econômica, com vistas a assegurar a todos a existência digna, conforme os ditames da justiça social (SILVA, 2000, p. 141).

E estes fins sociais, devem estar equacionados de forma clara com o poder estatal e o poder econômico, que são responsáveis pela formação das receitas públicas, conforme ressalta José Afonso Silva, ao comentar sobre o sistema tributário. Segundo ele, o sistema tributário é o conjunto de instituições, regras e práticas tributárias, seja nas suas relações, seja quanto aos efeitos globalmente produzidos sobre a vida econômica e social.

E, que não basta a "mera enumeração de tributos para se ter um sistema” (SILVA, 2000, p. 18). Compreende muito mais do isso, ou seja, que o sistema jurídico tributário esteja em harmonia com o ordenamento econômico e financeiro, com as propostas e metas de desenvolvimento nacional, visando à mesma finalidade: satisfação das necessidades da população e o desenvolvimento econômico e social.

Por isso, merece destacar a importância do estudo da ordem econômica e da ordem social bem como a importância da incidência e arrecadação tributária para o desenvolvimento

\footnotetext{
${ }^{6}$ São programáticas as normas constitucionais através das quais o constituinte, em vez de regular, direta e imediatamente, determinados interesses, limitou-se a traçar os princípios para serem cumpridos pelos seus órgãos (...), como programas das respectivas atividades, visando à realização dos fins sociais do Estado. Cf. SILVA, José Afonso da. Aplicabilidade das normas constitucionais. $4^{\mathrm{a}}$ ed. São Paulo: Malheiros, 2000, p. 138.
}

Revista de Direito Tributário e Financeiro | e-ISSN: 2526-0138 | Maranhão | v. 3 | n. 2 | p. 23 - 44 | Jul/Dez. 2017. 
econômico e social do país. Assim, pode-se aferir que por ordem econômica pode ser designado como o conjunto de relações pertinentes à produção e à circulação da riqueza. Já, por sua vez a ordem social é considerada como o conjunto de relações pertinentes à distribuição de riquezas. Um dos instrumentos de intervenção do Estado na economia pode-se afirmar que é a atividade de tributação. Tal atividade tem por objetivo a interferência do Estado na economia. Com o tributo extrafiscal pretende o Estado exercer influência nas relações de produção e circulação da riqueza.

Com efeito, a intervenção do Estado pode ocorrer com uma série de medidas tanto com tributação mais acentuada ou menos acentuada, inclusive com incentivos fiscais com finalidades de estimular a ampliação do parque industrial, o comércio de bens e serviços entre outros, com políticas fiscais estabelecidas em conformidade com os ditames constitucionais. Daí a afirmativa de Hugo de Brito Machado de que "não constitui novidade a afirmação de que o tributo é uma arma valiosa de reforma social” (MACHADO, 1987, p. 12).

A tributação tem demonstrado que é excelente instrumento para o direcionamento da economia, vez que permite que sejam alcançados os fins sociais. $\mathrm{O}$ tributo é instrumento da economia de mercado, da livre iniciativa econômica (MACHADO, 1987, p. 13/4). Por isso dizer que deve ser estimulada a iniciativa de industrialização, de exportação, de atração de novos investimentos de capital. Tudo isto, ressalvando que através da efetiva aplicação dos princípios constitucionais, pode-se obter um maior resultado entre o desenvolvimento econômico e social, com maior tributação que alcance àqueles que suportam maior capacidade contributiva.

Enfim, no tocante às implicações da tributação com o desenvolvimento econômico, é patente de que a questão essencial não reside, somente, na menor ou na maior carga tributária, mas no modo pelo qual a carga tributária é distribuída. Todo tributo incide, em última análise, sobre a riqueza. Daí os dizeres de Aliomar Baleeiro:

Uma política tributária, para ser racional, há de manter o equilíbrio ótimo entre o consumo, a produção, a poupança, o investimento e o pleno emprego. Se houver hipertrofia de qualquer desses aspectos em detrimento dos outros, várias perturbações podem suceder com penosas consequências para a coletividade (BALEEIRO, 1981, p. 171).

E neste patamar o poder público deverá verificar se é possível aumentar ou diminuir 
a carga tributária, e a possibilidade de redistribuir a renda sem prejuízo do desenvolvimento econômico. Nesta feita, sustenta Hugo de Brito Machado (MACHADO, 1987, p.28) que o Estado deve intervir no processo de desenvolvimento econômico, pela tributação, não para conceder incentivos fiscais à formação de riqueza individual, mas para ensejar a formação de empresas cujo capital seja dividido por número significativo de pessoas, de sorte que a concentração de capital se faça sem que necessariamente isto signifique concentração individual de riqueza. Na busca de uma sociedade que ofereça melhor qualidade de vida deve ser definitivamente afastado o caminho da estatização da economia. O Estado, como órgão do poder político institucionalizado, certamente deve intervir na atividade econômica. Mas deve fazer com o mínimo de sacrifício para a liberdade do contribuinte.

Para que o Estado retome o seu compromisso com a equidade tributária e torne mais eficaz as suas ações voltadas à justiça social e à proteção dos mais pobres, a observância das seguintes diretrizes gerais impõe-se como necessária em qualquer debate sobre a reforma da legislação tributária, conforme afirmativa de Henrique Alves (ALVES, 2012, p. 71): diminuir, ao máximo, o peso da carga tributária indireta; conferir, à incidência tributária direta, a maior progressividade possível; conferir, à incidência tributária indireta, a maior seletividade (em função da essencialidade dos produtos) possível.

Ao lado das medidas de natureza tributária, são indispensáveis medidas no plano da despesa pública. Isto requer que o produto da arrecadação de tributos seja empregado preferentemente nos setores sociais, de saúde pública entre outros interesses da sociedade. E mais: Um dos temas centrais da discussão da repercussão dos tributos está na justiça social, em cujo núcleo está o problema do justo tributário.

O professor Roberto Wagner Nogueira (NOGUEIRA, 2008, p. 240) destaca que é impossível pensar a justiça tributária sem dever ético de pagar o justo tributo. Por isso é preciso a sociedade brasileira avançar nos debates tributários, para enfim, acabar de vez com discursos que negam ao tributo, sua qualidade principal, que é o de ser instrumento financeiro indispensável à realização da justiça tributária, e, por conseguinte, justiça social.

\section{CONCLUSÕES}

Revista de Direito Tributário e Financeiro | e-ISSN: 2526-0138 | Maranhão | v. 3 | n. 2 | p. 23 - 44 | Jul/Dez. 2017. 
Uma legítima política pública tributária deve ser fundada em diversos fatores e não apenas baseada na sua arrecadação procedida pelo Estado. Referida política deve atender os ditames constitucionais, visando o desenvolvimento econômico e social, garantindo os direitos do contribuinte.

$\mathrm{Na}$ busca do bem comum, os princípios constitucionais funcionam como fundamentos de todo o sistema normativo. Os princípios constitucionais são de fundamental importância para a estruturação do Estado brasileiro, na medida em que traduzem quais são os fundamentos e principais objetivos do Estado, e, consequentemente, orientam toda política sócio econômica desenvolvida pelo Poder Executivo.

Os princípios que regulam tanto a ordem econômica, quanto a ordem social são instrumentos previstos no texto constitucional visando a preservação dos direitos sociais do cidadão, como forma de se alcançar a justiça social, a qual somente poderá ser atingida se vier coadunada com o princípio da dignidade da pessoa humana e da justiça fiscal. A administração pública ao cobrar tributos, deverá retornar estes valores à sociedade, através da execução de serviços públicos.

De igual modo o Estado poderá atender suas finalidades através da distribuição de riqueza, satisfação das necessidades sociais, de políticas de investimentos, entre outras, que podem ser alcançadas por meio de uma política tributária e não necessariamente pela imposição tributária. Por isso, é necessário repensar o papel do Estado, na função arrecadatória e na prestação de serviços aos jurisdicionados. Somente com a socialização dos tributos, através da sua aplicação como instrumento social é que será possível desenvolver uma política social justa e distributiva, como forma de se alcançar as finalidades a que o Estado se prestou a desenvolver.

Para que o Estado alcance suas finalidades sócio econômicas e desenvolva uma política governamental em prol dessas finalidades, faz-se necessário o respeito ao princípio da justiça fiscal, o qual somente poderá ser alcançado mediante a conjugação dos princípios da igualdade e seus corolários, em conjunto com o princípio da função social do tributo, possibilitando aos cidadãos viver com dignidade.

Assim, pode-se afirmar que a tributação social é aquela que respeita o que é inerente à sociedade no contexto social dos ditames constitucionais. Por isso, a tributação deve privilegiar as necessidades essenciais da sociedade, destacando-se entre elas a alimentação, a 
saúde, a moradia, a educação, o acesso ao trabalho, a livre iniciativa e a livre concorrência. Conclui-se, que não é preciso nenhuma reforma constitucional para que os parâmetros da justiça social sejam alcançados. Ao contrário, o que se faz necessário é justamente o efetivo e integral respeito à Constituição Federal. O tributo como eficaz instrumento de Justiça Social depende da atuação conjunta do Poder Legislativo, Executivo e Judiciário, no cumprimento da Carta constitucional e na implementação das políticas públicas pertinentes.

\section{REFERÊNCIAS BIBLIOGRÁFICAS}

ALVES, Henrique Napoleão. Tributação e injustiça social no Brasil in Revista Espaço Acadêmico, $\mathrm{n}^{\circ}$ 133. Junho 2012, ano XII.

BALEEIRO, Aliomar. Uma Introdução à Ciência das Finanças, Rio de Janeiro, Forense, 1981.

BASTOS. Celso Ribeiro. Curso de direito econômico. São Paulo: Celso Bastos Editor, 2003. BECKER, Alfredo Augusto. Teoria Geraldo Direito Tributário. Saraiva, São Paulo, 1963.

CARRAZZA, Roque Antonio. Curso de direito constitucional tributário. São Paulo: Malheiros, 2015.

CASTILHO, Paulo Cesar Baria de. Confisco Tributário. São Paulo: Revista dos Tribunais, 2002.

CONTI, José Maurício. Princípios tributários da capacidade contributiva e da progressividade. São Paulo: Dialética, 1997.

DERZI, Mizabel. Família e Tributação. A vedação constitucional de se utilizar o tributo com efeito de confisco In Revista da Faculdade de Direito da UFMG, 1989, v. 32.

FERREIRA, Alexandre Henrique Salema. Tributação e Justiça Social. Qualitas Revista Eletrônica. Volume 5 - 2006, n.1.

FONSECA. João Bosco Leopoldino da. Direito econômico. $2^{\mathrm{a}}$ ed. Rio de Janeiro: Forense, 1998.

LEONETTI, Carlos Araújo. Humanismo e Tributação. Disponível em www.egov.ufsc.br/portal/sites/default/files/anexos/21045-21046-1-PB.pdf. Acesso em 10.ago.2017.

MACHADO, Hugo de Brito. A Função Social do Tributo nas Ordens Econômica, Social e Política, in Revista da Faculdade de Direito de Fortaleza, 28 (2) : jul-dez, 1987.

MARTINS, Ives Gandra da Silva. Direito constitucional interpretado. São Paulo: Revista dos Tribunais, 1992.

A Defesa do Contribuinte na Constituição Federal, in A Defesa do Contribuinte no Direito Brasileiro, São Paulo: IOB, 2002.

Direito Econômico e Tributário - Comentários e Pareceres. São

Paulo: Ed. Resenha Tributária, 1992.

MELLO, Gustavo Miguez de. Uma visão interdisciplinar dos problemas jurídicos, econômicos, sociais, políticos e administrativos relacionados com uma reforma tributária in Temas para uma nova estrutura tributária no Brasil. Mapa Fiscal Editora, Sup. Esp. I Congresso Bras. de Direito Financeiro, Rio de Janeiro, 1978.

Revista de Direito Tributário e Financeiro | e-ISSN: 2526-0138 | Maranhão | v. 3 | n. 2 | p. 23 - 44 | Jul/Dez. 2017. 
MORAES, Germana de Oliveira. A Reforma Tributária desejável. In Revista CEJ, Brasília, n. 24, jan./mar. 2004.

NOGUEIRA, Roberto Wagner Lima. Direito tributário, linguagem e método, $2^{\mathrm{a}}$ ed. São Paulo: Noeses, 2008.

OLIVEIRA, João Marcos Domingues de. Capacidade contributiva. Rio de Janeiro: Renovar, 1988.

PONTES, Helenilson Cunha Pontes. O princípio da proporcionalidade e o direito tributário. São Paulo: Dialética, 2000.

RIBEIRO, Marcelo Gollo. Tributação e Justiça Social: uma perspectiva filosófica. In Disponível em https://jus.com.br/artigos/23866/tributacao-e-justica-social-uma-perspectivafilosofica . 2013. Acesso em 05.ago.2017.

RIBEIRO, Maria de Fátima. Considerações sobre o imposto de renda na constituição de 1988. São Paulo: Editora Resenha Tributária, 1990.

RODRIGUES, Rafael Moreno. Intributabilidade dos Gêneros Alimentícios Básicos. São Paulo, Resenha Tributária, 1981.

SILVA, José Afonso da. Aplicabilidade das normas constitucionais. $4^{\mathrm{a}}$ ed. São Paulo: Malheiros, 2000.

TIPKE, Klaus e YAMASHITA, Douglas. Justiça fiscal e princípio da capacidade contributiva. São Paulo: Malheiros, 2002.

WAGNER, José Carlos Graça. Tributação Social do Trabalho e do Capital. SP, Resenha Tributária, 1982.

Resenha Tributária, 1979.

Penalidades e Acréscimos na Legislação Tributária. . São Paulo: 